\title{
Effects of process parameters on mechanical and metallurgical properties of AA5083 weld bead and optimization by using Taguchi based Grey Relational Analysis and ANOVA of submerged friction stir welding
}

\author{
Laxmanaraju Salavaravu* and Lingaraju Dumpala** \\ * Department of Mechanical Engineering, JNTUK, Kakinada, Andhra Pradesh, India. \\ ** Department of Mechanical Engineering, UCEK, JNTUK, Kakinada, Andhra Pradesh, India. \\ *Corresponding Author: laxman.raju@yahoo.co.in
}

Submitted : 30/03/2020

Revised : :14/09/2021

Accepted : 26/09/2021

\begin{abstract}
Friction stir welding (FSW) can be made to improve the mechanical properties in the weld zone. This article aims to obtain the optimum FSW process parameters for two plates of AA5083 welded joints. The significant factors in the FSW process are tool rotational speed(TRS) and tool transverse speed (TTS), and the weld process conditions are Submerged FSW and Normal FSW. For doing the investigation, the Taguchi method L18 orthogonal array design of experimentation is utilized. Using the Grey Relational Analysis(GRA)to calculate the grey relation grade, the response parameters are tensile strength, microhardness, and surface roughness. The optimum process parameters have been recognized, and ANOVA controls the significant contribution of process parameters. The optimal FSW process parameters are used to maximize the FSW joint strength. It is identified in the condition of Submerged FSW, high tool rotational speed, and low TTS.
\end{abstract}

Keywords: Submerged friction stir welding (Submerged FSW); Normal Friction stir welding (Normal FSW); Mechanical properties; Taguchi method; Grey Relational Analysis.

\section{INTRODUCTION}

Welding of atypical materials with suitable mechanical properties and a good surface finish is required to manufacture joints. FSW is a solid-state joining process with no melting of the metal. It joins two butted faces of like or unlike metals using a nonconsumable tool. The combination welding of aluminum alloys is commonly not favored because of hot cracking and compound isolation issues. The Submerged FSW (SFSW) can keep up constant and low heat generation near the welded line and control the heat-affected zone (HAZ) (Sabari et al., 2016). The tool pin shapes, the tapered cylindrical pin tool will altogether affect the mechanical strength of the weld joints at a higher rotational speed that the material could be moved from the forward to backward of the tool 
sufficiently (Fujii et al., 2006 and Suresha et al., 2011). The Submerged FSW experiments are conducted and analyzed with the weld joints having lower ultimate temperature and less grain development. Subsequently, improved grain structure and excellent mechanical properties led to superior ductile properties (Darras et al., 2013; Hofmann et al., 2005; Shanavas et al., 2018; and Pedapati et al., 2017).In the FSW, plastic deformation occurs at an eminent temperature and makes almost the phase showing refined grains (Jata et al., 2000; Liu et al., 1997). The failure-free, high-productivity welded joints know how to be generated using an extensive scope of process parameters. Hardness analysis showed the most reduced hardness within the HAZ on the AA5083 sides, wherever failures were seen to occur (Koilraj et al.,2012).

Taguchi method created through Taguchi and Konishihas been primarily used in engineering analysis purposes to optimize the presentation qualities by methods for the best sequence of operational parameters. Taguchi technique has been precise as a dominant tool instead of the optimal principle opinion about quality attributes, execution, and computational expenses during a straightforward addition (Taguchi 1986 and 1987, and Konishihas et al., 2017). The Greytheory deals with the issues of utilizing insufficient data and breaks down the relationship along with process parameters and responses (Deng et al., 1989). FSW process parameters are multi-response optimization: TTS, axial load, TRS, and \% of reinforcement representing FSW of AA6061(Dinesh et al., 2019). The impact factor on the tensile strength of the joint is that TRS is the high contribution, and it is broken down by utilizing Taguchi-based GRA (Vijayan et al., 2010and ParvizAsadi et al., 2016). The different optimization techniques are used to analyze the optimum process parameters and improve the quality measures. Initially, the Taguchi- Data envelopment analysis based ranking (DEAR) is a multi-response decision making that has been proposed to obtain the optimal combination process parameters (Huu Phan et al., 2020). The MRR is analyzed using Taguchi methods to identify the main significant factors influencing the MRR (Huu Phan et al., 2021). When the TOPSIS method is combined with the Taguchi method, they obtain several optimized process parameters, reduce the experiment's cost and time, and solve the multi-objective optimization problem (Huu Phan et al., 2016). The optimization techniques, Deng's computation as the most appropriate MCDM approach in PMEDM, are investigated compared with TOPSIS, GRA, and PSI (Huu, 2020). An attempt has been made to implement TOPSIS-based multi-response optimization to investigate the effects of low-frequency vibration on MRR and Surface Roughness in EDM (Phan Nguyen et al., 2018). In dissimilar FSW capability of AA7075 and AA6013-T6 in applying the Taguchi-based GRA,the welded joint's optimum process condition was determined by considering the $\%$ of contribution effect orderly TRS, TPP, and TTS(Kasman et al., 2019). Earlier studies obtained the improvementsof Submerged FSW more than Normal FSW weld joints relating to the strength improvement to get the maximum mechanical properties by applying optimization methods.

Many researchers are focusing on the mechanical properties of FSW and the impact of process parameters as TRS and TTS in addition to the type of FSW processes that have been widely investigated process parameters such as TRS and TTS in addition to the type of FSW processes that have been widely investigated. The present work focuses on air as normal FSW, performed in submerged seawater, i.e., submerged FSW, for the importance in the strength and the mechanical properties where the specimens are entirely submerged in seawater. The parameters selected for the input are TTS, TRS, and the response parameters are UTS, microhardness, and surface roughness. Investigational results were statistically processed through the Taguchi method, GRA, and ANOVA, predicting the optimum process parameter of Submerged and Normal FSW conditions.

\section{EXPERIMENTATION}

AA5083 of $250 \mathrm{~mm}$ in length, $6 \mathrm{~mm}$ in thickness, and $60 \mathrm{~mm}$ in width plate is used in this experimentation. Chemical composition, in addition to mechanical properties, is arranged in Tables $1 \& 2$ given below. Samples of AA5083 plates are butt welded under seawater and generally in the air by FSW process experimental setup as shown in Figures 1 (a) \&(b). 
184 Effects of process parameters on mechanical and metallurgical properties of AA5083 weld bead and optimization by using Taguchi based Grey Relational Analysis and ANOVA of submerged friction stir welding

Table 1. AA5083 aluminum alloys chemical composition of (weight \%).

\begin{tabular}{|l|c|c|c|c|c|c|c|c|c|}
\hline Element & $\mathrm{Si}$ & $\mathrm{Cu}$ & $\mathrm{Fe}$ & $\mathrm{Mg}$ & $\mathrm{Mn}$ & $\mathrm{Zn}$ & $\mathrm{Cr}$ & $\mathrm{Ti}$ & $\mathrm{Al}$ \\
\hline Wt.\% & 0.4 & 0.1 & 0.4 & $4.0-4.9$ & $0.4-0.1$ & 0.15 & 0.25 & $0.05-0.25$ & bal \\
\hline
\end{tabular}

Table 2. AA5083 mechanical properties.

\begin{tabular}{|c|c|}
\hline Property & Value \\
\hline Proof Stress & $125 \mathrm{Min} \mathrm{MPa}$ \\
\hline Ultimate Tensile Strength & $275-350 \mathrm{MPa}$ \\
\hline Vickers Hardness & $81 \mathrm{HV}$ \\
\hline
\end{tabular}

The FSW process is done normally in air and under seawater on an FSW-3TN-NC machine. The Normal FSW machine setup is converted into a Submerged FSW setup shown in Figures 1a and b. The cylindrical taper tool is made of $\mathrm{H} 13$ tool steel, and it is $18 \mathrm{~mm}$ in shoulder diameter with a $5.8 \mathrm{~mm}$ long pin, $6 \mathrm{~mm}$ in a larger diameter, and $3 \mathrm{~mm}$ in a smaller diameter.
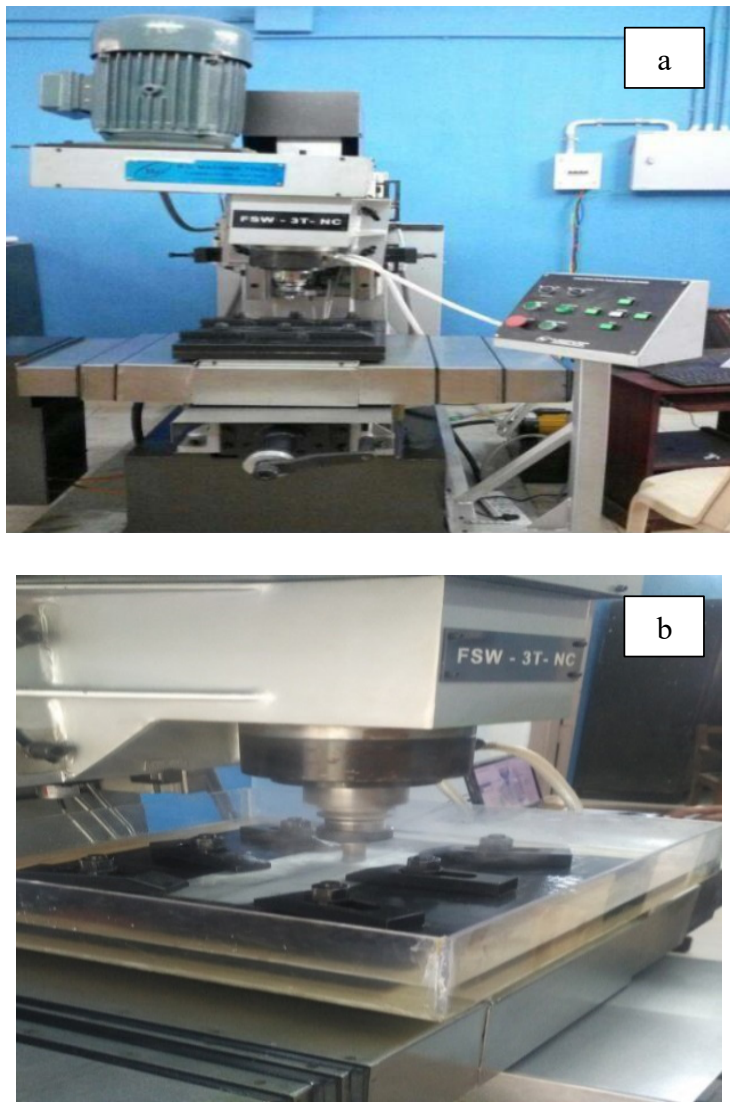

Figure 1. a) Normal FSW experimental setup. b) Submerged FSW experimental setup. 
The alloy plates are welded at several TRSs and transverse speeds. The welding tool rotated counterclockwise, and the tilt angle was $1^{\circ}$ from the normal surface of the workbench. Greasy and oxide film is cleaned with ethanol before welding. In the Submerged condition, the poured water is collected from the sea in the Kakinada seashore. The seawater is used to do the Submerged FSW experiment. The welded plates are shown in Figure 2. The welded plates are cut vertically to the welding path by utilizing a water jet cutting machine by the required dimensions of the specimens.

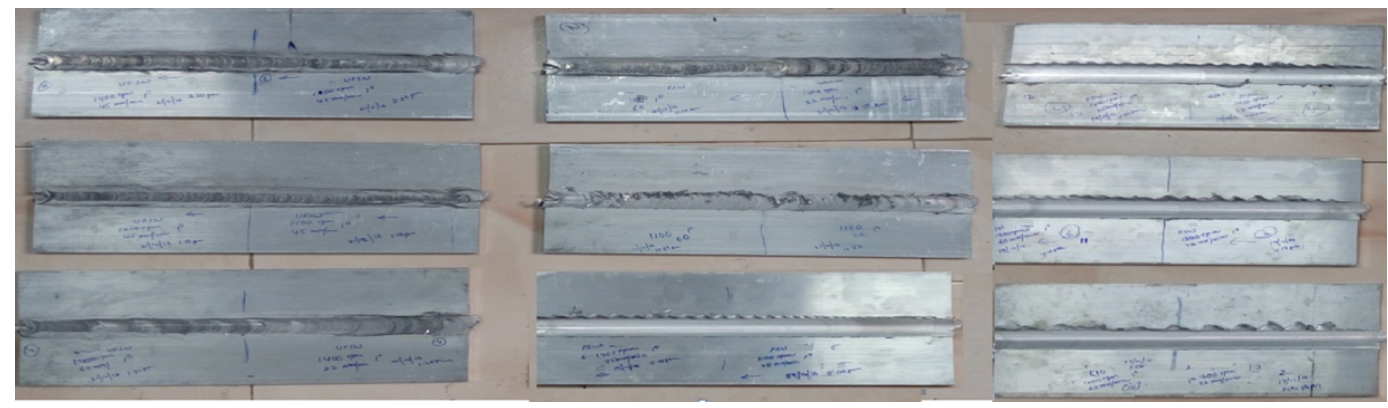

Figure 2. Submerged FSW and Normal FSW welded specimens.

The tensile specimens are prepared using ASTM D-358 standard dimensions shown in Fig. 3 and tested using computerized UTM (INSTRON-8801) as shown in Fig.4.The microhardness specimens are prepared along the cross-section of the welded workpiece. Vickers microhardness is measured with an MH-5D digital hardness analyzer over the weld zone, and a load of $300 \mathrm{grams}$ and a stay time of 10 seconds is applied.

Microstructures of the fracture surface of the FSW joint fracture tensile test samples are scanned by using a scanning electron microscope (SEM) fitted out with an energy-dispersive X-ray spectroscope (EDS). After the sample is milled and polished joint is washed multiple times with etching solution $2 \mathrm{ml} \mathrm{HF}+5 \mathrm{ml}$ HNO3+95mlpurified water for the $\mathrm{Al}$ alloy by applying a cotton ball, awaiting noticeable etching is obtained. Also, the samples are cleaned with ethanol following a couple of moments of washing.

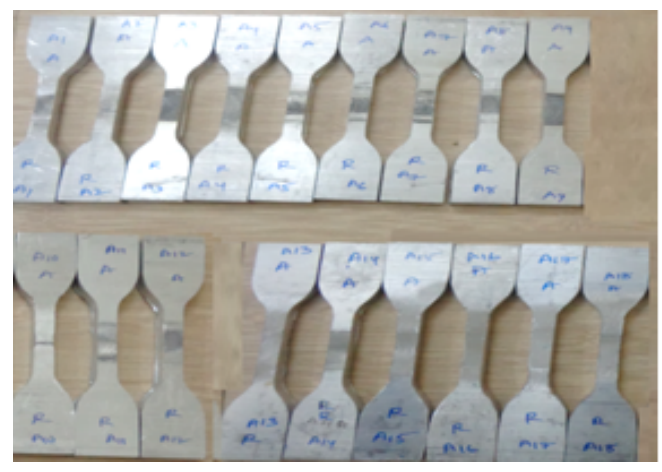

Figuire 3. Tensile specimens.

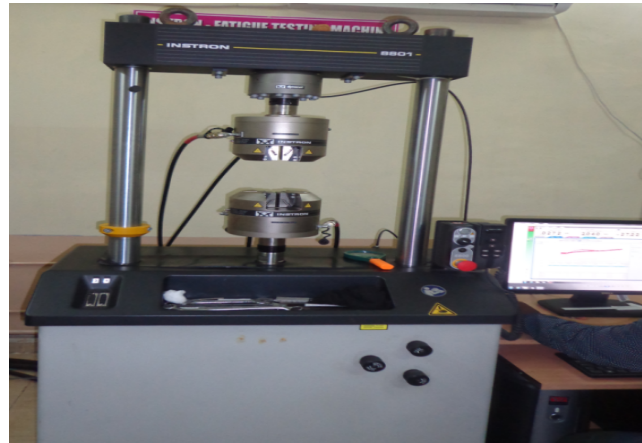

Figure 4. UTM (INSTRON-8801).

\subsection{Taguchi-Grey Relation Analysis:}

Taguchi technique is an additional powerful tool to develop the best quality techniques. This coordinated methodology is straightforward yet effective in obtaining the best design scope with execution, quality, and mathematical expense. 


\section{Step 1: Taguchi Method}

The larger, the better for the $\mathrm{S} / \mathrm{N}$ ratio $-10 \log _{10} \frac{1}{n} \sum_{i=1}^{n} \frac{1}{y_{i}^{2}}$

The smaller, the better for the $\mathrm{S} / \mathrm{N}$ ratio $-10 \log _{10} \frac{1}{n} \sum_{i=1}^{n} y_{i}^{2}$

Step 2:Normalization of $\mathrm{S} / \mathrm{N}$ ratios between 0 and 1 using Eq. 3 and Eq. 4.

$\mathrm{k}=1$ to $\mathrm{n}, \mathrm{i}=1$ to 18 , where $\mathrm{n}$ is the performance attribute, and $\mathrm{i}$ is the experimental number. $\mathrm{x}_{\mathrm{i}}^{*}(\mathrm{k})$ is the significance subsequently grey relational generation, the minimum is $x_{i}^{*}(k)$, which is the lowest value of $x_{i}^{*}(k)$, and $\max x_{i}^{0}(k)$ is the highest value of $x_{i}^{0}(k)$.

This is the larger, the better:

$\mathrm{x}_{\mathrm{i}}^{*}(\mathrm{k})=\frac{\mathrm{x}_{\mathrm{i}}^{\mathrm{o}}(\mathrm{k})-\min \mathrm{x}_{\mathrm{i}}^{\mathrm{o}}(\mathrm{k})}{\max \mathrm{x}_{\mathrm{i}}^{\mathrm{O}}(\mathrm{k})-\min \mathrm{x}_{\mathrm{i}}^{\mathrm{o}}(\mathrm{k})}$

This is the smaller, the better:

$$
\mathrm{x}_{\mathrm{i}}^{*}(\mathrm{k})=\frac{\max \mathrm{x}_{\mathrm{i}}^{\mathrm{o}}(\mathrm{k})-\mathrm{x}_{\mathrm{i}}^{\mathrm{o}}(\mathrm{k})}{\max \mathrm{x}_{\mathrm{i}}^{\mathrm{k}}(\mathrm{k})-\min \mathrm{x}_{\mathrm{i}}^{\mathrm{O}}(\mathrm{k})}
$$

Step 3:To evaluate the grey relational coefficient (GRC)using Equation 5.

The grey relation coefficient $\xi_{i}(k)$ can be determined as follows:

$$
\xi_{i}(k)=\frac{\Delta_{\min }+\zeta \Delta_{\max }}{\Delta_{o i}(\mathrm{k})+\zeta \Delta_{\max }}
$$

Step 4: To calculate the grey relational grade (GRG) by using Equation 6:

$$
\frac{1}{n} \sum_{i=1}^{n} \xi_{i}(k)=\gamma_{i}
$$

Step: 5: To analyze variance (ANOVA) using MINITAB-17 statistical software for process parameter contribution percentage to identify the optimal level GRG value. Three input parameters are the type of weld process conditions, TRS, and TTS is considered to examine their primary impact on output parameters surface roughness, UTS, and microhardness. L18 OA of Taguchi is presented in Table 4.

Table 3. FSW process parameters are arranged in a tabular form.

\begin{tabular}{|c|c|c|c|c|}
\hline \multirow{2}{*}{$\begin{array}{c}\text { Parameter } \\
\text { designation }\end{array}$} & Process parameter & \multicolumn{3}{|c|}{ LEVELS } \\
\cline { 3 - 5 } & & Level 1 & Level2 & Level3 \\
\hline $\mathrm{T}$ & Type of Welding Process-T & NFSW & SFSW & $* * * *$ \\
\hline $\mathrm{N}$ & Tool Rotational Speed (rpm)-N & 1100 & 1250 & 1400 \\
\hline $\mathrm{F}$ & Tool Transverse speed(mm/min)-F & 22 & 45 & 60 \\
\hline
\end{tabular}




\section{RESULTS AND DISCUSSION}

In advance, the effect of process parameters is on combined responses found by using GRA. In the GRA, the Taguchi-based S/N ratio is used to solve the GRG and calculates the ranking. All the significances of GRC on behalf of 18 experiments are determined using Eq. [5]. GRGs for all operation properties are controlled using Eq. [6].

Table 4. Test results and $\mathrm{S} / \mathrm{N}$ ratios data.

\begin{tabular}{|c|c|c|c|c|c|c|c|c|c|}
\hline \multirow{2}{*}{ Expt No } & \multicolumn{3}{|c|}{ Process parameters } & \multicolumn{3}{|c|}{ Test Results } & \multicolumn{3}{|c|}{$\mathrm{S} / \mathrm{N}$ ratios } \\
\hline & $\mathbf{T}$ & $\mathbf{N}$ & $\mathbf{F}$ & UTS(Mpa) & $\operatorname{Ra}(\mu \mathrm{m})$ & HV & UTS & $\mathbf{R a}$ & HV \\
\hline 1 & SFSW & 1100 & 22 & 154.85 & 0.84 & 94 & 43.798 & 1.514 & 39.463 \\
\hline 2 & SFSW & 1100 & 45 & 148.78 & 0.91 & 91 & 43.451 & 0.819 & 39.181 \\
\hline 3 & SFSW & 1100 & 60 & 146 & 0.96 & 88 & 43.287 & 0.355 & 38.89 \\
\hline 4 & SFSW & 1250 & 22 & 167.41 & 0.76 & 98 & 44.476 & 2.384 & 39.825 \\
\hline 5 & SFSW & 1250 & 45 & 157.73 & 0.81 & 96 & 43.958 & 1.83 & 39.645 \\
\hline 6 & SFSW & 1250 & 60 & 155.99 & 0.86 & 94 & 43.862 & 1.31 & 39.463 \\
\hline 7 & SFSW & 1400 & 22 & 175.63 & 0.57 & 109 & 44.892 & 4.883 & 40.749 \\
\hline 8 & SFSW & 1400 & 45 & 165.32 & 0.66 & 103 & 44.367 & 3.609 & 40.257 \\
\hline 9 & SFSW & 1400 & 60 & 160.06 & 0.75 & 96 & 44.086 & 2.499 & 39.645 \\
\hline 10 & NFSW & 1100 & 22 & 150.95 & 0.92 & 92 & 43.577 & 0.724 & 39.276 \\
\hline 11 & NFSW & 1100 & 45 & 143.35 & 0.97 & 88 & 43.128 & 0.265 & 38.89 \\
\hline 12 & NFSW & 1100 & 60 & 136.58 & 0.98 & 85 & 42.708 & 0.175 & 38.588 \\
\hline 13 & NFSW & 1250 & 22 & 163.33 & 0.72 & 93 & 44.261 & 2.853 & 39.37 \\
\hline 14 & NFSW & 1250 & 45 & 153.49 & 0.82 & 91 & 43.722 & 1.724 & 39.181 \\
\hline 15 & NFSW & 1250 & 60 & 147.04 & 0.96 & 89 & 43.349 & 0.355 & 38.988 \\
\hline 16 & NFSW & 1400 & 22 & 168.16 & 0.64 & 103 & 44.514 & 3.876 & 40.257 \\
\hline 17 & NFSW & 1400 & 45 & 158.35 & 0.78 & 98 & 43.992 & 2.158 & 39.825 \\
\hline 18 & NFSW & 1400 & 60 & 154.05 & 0.8 & 94 & 43.753 & 1.938 & 39.463 \\
\hline
\end{tabular}

Weightage in operating properties of Ra, HV, and UTS is $0.2,0.3$, and 0.5 , respectively [Kundu et al.], including evidence regarding the significance of the output parameter in favor of the actual application. The GRC and resultant GRG for every experiment are calculated and listed in Table 5. From Table 5, the GRG value is higher at experiment 7, indicating the superior quality properties created on the greater GRG; the optimum level of every controllable factor is regulated. 
188 Effects of process parameters on mechanical and metallurgical properties of AA5083 weld bead and optimization by using Taguchi based Grey Relational Analysis and ANOVA of submerged friction stir welding

Table 5. Normalization, Deviation Sequence, GRC, and GRG Data.

\begin{tabular}{|c|c|c|c|c|c|c|c|c|c|c|c|}
\hline \multirow{2}{*}{$\begin{array}{c}\text { Expt } \\
\text { NO } \\
\end{array}$} & \multicolumn{3}{|c|}{ Normalization } & \multicolumn{3}{|c|}{ Deviation sequence } & \multicolumn{3}{|c|}{ GRC } & \multirow{2}{*}{ GRG } & \multirow{2}{*}{ Rank } \\
\hline & UTS & $\mathbf{R a}$ & HV & UTS & $\mathbf{R a}$ & HV & UTS & $\mathbf{R a}$ & HV & & \\
\hline 1 & 0.499 & 0.716 & 0.405 & 0.501 & 0.284 & 0.595 & 0.500 & 0.637 & 0.457 & 0.171 & 11 \\
\hline 2 & 0.340 & 0.863 & 0.274 & 0.660 & 0.137 & 0.726 & 0.431 & 0.785 & 0.408 & 0.165 & 15 \\
\hline 3 & 0.265 & 0.962 & 0.140 & 0.735 & 0.038 & 0.860 & 0.405 & 0.929 & 0.368 & 0.166 & 13 \\
\hline 4 & 0.810 & 0.531 & 0.572 & 0.190 & 0.469 & 0.428 & 0.724 & 0.516 & 0.539 & 0.209 & 3 \\
\hline 5 & 0.572 & 0.648 & 0.489 & 0.428 & 0.352 & 0.511 & 0.539 & 0.587 & 0.495 & 0.178 & 8 \\
\hline 6 & 0.528 & 0.759 & 0.405 & 0.472 & 0.241 & 0.595 & 0.515 & 0.675 & 0.457 & 0.176 & 9 \\
\hline 7 & 1.000 & 0.000 & 1.000 & 0.000 & 1.000 & 0.000 & 1.000 & 0.333 & 1.000 & 0.289 & 1 \\
\hline 8 & 0.760 & 0.271 & 0.772 & 0.240 & 0.729 & 0.228 & 0.675 & 0.407 & 0.687 & 0.208 & 4 \\
\hline 9 & 0.631 & 0.506 & 0.489 & 0.369 & 0.494 & 0.511 & 0.575 & 0.503 & 0.495 & 0.179 & 7 \\
\hline 10 & 0.398 & 0.883 & 0.318 & 0.602 & 0.117 & 0.682 & 0.454 & 0.811 & 0.423 & 0.172 & 10 \\
\hline 11 & 0.192 & 0.981 & 0.140 & 0.808 & 0.019 & 0.860 & 0.382 & 0.963 & 0.368 & 0.165 & 16 \\
\hline 12 & 0.000 & 1.000 & 0.000 & 1.000 & 0.000 & 1.000 & 0.333 & 1.000 & 0.333 & 0.156 & 18 \\
\hline 13 & 0.711 & 0.431 & 0.362 & 0.289 & 0.569 & 0.638 & 0.634 & 0.468 & 0.439 & 0.181 & 6 \\
\hline 14 & 0.464 & 0.671 & 0.274 & 0.536 & 0.329 & 0.726 & 0.483 & 0.603 & 0.408 & 0.161 & 17 \\
\hline 15 & 0.293 & 0.962 & 0.185 & 0.707 & 0.038 & 0.815 & 0.414 & 0.929 & 0.380 & 0.169 & 12 \\
\hline 16 & 0.827 & 0.214 & 0.772 & 0.173 & 0.786 & 0.228 & 0.743 & 0.389 & 0.687 & 0.218 & 2 \\
\hline 17 & 0.588 & 0.579 & 0.572 & 0.412 & 0.421 & 0.428 & 0.548 & 0.543 & 0.539 & 0.181 & 5 \\
\hline 18 & 0.478 & 0.626 & 0.405 & 0.522 & 0.374 & 0.595 & 0.489 & 0.572 & 0.457 & 0.165 & 14 \\
\hline
\end{tabular}

The mean GRG and the optimum levels of the elements are presented in Table 6 . The optimum levels of the process parameters founded on the GRG are $\mathrm{T}_{2} \mathrm{~N}_{3} \mathrm{~F}_{1}$. It is the optimum level of the process parameter at submerged FSW, higher TRS $1400 \mathrm{rpm}$, and low TTS $22 \mathrm{~mm} / \mathrm{min}$. Fig. 5 shows a clear view of the process parameters and depicts the TRS increases, TTS decreases and submerged FSW conditions get high GRG value. The optimum process condition of the higher TRS, low tool feed rate, and Submerged FSW reveals that there is no defect due to sufficient heat generation between tool and workpiece, and it contains more refined grains in the weld zone. 

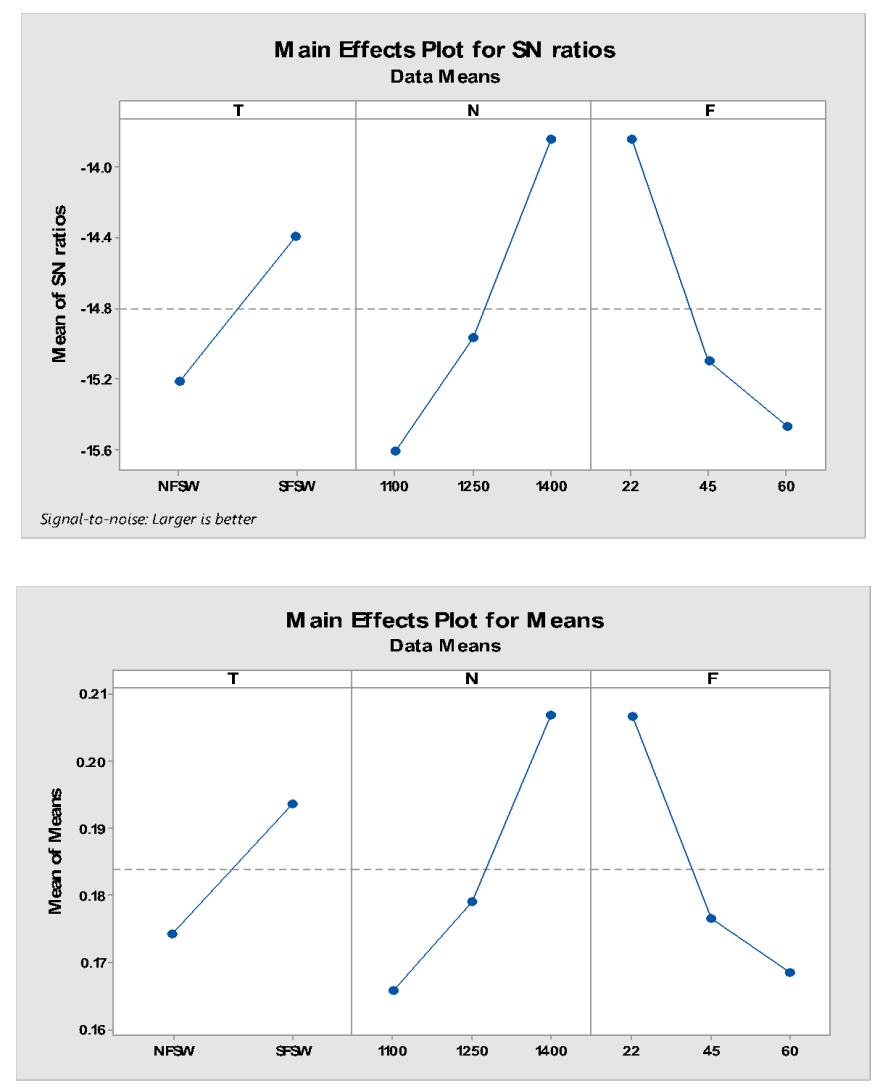

Figure 5. Response graphs of $\mathrm{S} / \mathrm{N}$ ratio and mean of GRG.

The ANOVA for GRG is calculated and presented in Table 7. They were being carried away to analyze the consequences of the process parameter. The higher F-value specifies that the factor is well significant in affecting all the responses of the weld. The increased effect of the process parameters is defined as orderly TRS as 8.53, TTS as 7.69, and the type of weld nature is of the minor effect 5.33. The P-Values of all the process parameters are shown below as 0.05 . This means that the process parameters are the most significant factors. $\%$ of the contribution is at the process parameter TRS as 34.28 , TTS as 30.91 , the type of weld nature is 10.69 , and the error in this process parameter is 24.1 at DOF 12. Finally, experimentation's total degree of freedom is 17 . The predicted value is calculated based on the literature [2].

Table 6. Taguchi Analysis: GRG versus T, N, and F of S/N ratios and Means.

\begin{tabular}{|c|c|c|c|c|c|c|}
\hline \multicolumn{2}{|c|}{ Response Table for S/N RatiosLarger is better-GRG } & \multicolumn{3}{|c|}{ Response Table for Means } \\
\hline Level & $\mathrm{T}$ & $\mathrm{N}$ & $\mathrm{F}$ & $\mathrm{T}$ & $\mathrm{N}$ & $\mathrm{F}$ \\
\hline 1 & -15.21 & -15.61 & -13.84 & 0.1743 & 0.1658 & 0.2067 \\
\hline 2 & -14.39 & -14.96 & -15.10 & 0.1936 & 0.1792 & 0.1766 \\
\hline 3 & & -13.84 & -15.47 & & 0.2069 & 0.1686 \\
\hline Delta & 0.82 & 1.78 & 1.63 & 0.0193 & 0.0411 & 0.0382 \\
\hline Rank & 3 & 1 & 2 & 3 & 1 & 2 \\
\hline
\end{tabular}


Table 7. The ANOVA of GRG of UTS, Ra, and HV.

\begin{tabular}{|c|c|c|c|c|c|c|}
\hline Source & DF & Adj SS & Adj MS & F-Value & P-Value & \% of contribution \\
\hline $\mathrm{T}$ & 1 & 3.021 & 3.0208 & 5.33 & 0.040 & 10.69 \\
\hline $\mathrm{N}$ & 2 & 9.680 & 4.8401 & 8.53 & 0.005 & 34.28 \\
\hline $\mathrm{F}$ & 2 & 8.729 & 4.3644 & 7.69 & 0.007 & 30.91 \\
\hline Error & 12 & 6.806 & 0.5672 & & & 24.10 \\
\hline `Total & 17 & 28.236 & & & & \\
\hline
\end{tabular}

Predicted value of $\mathrm{GRG}=\mathrm{T}_{2}+\mathrm{N}_{3}+\mathrm{F}_{1}-2 \mathrm{~T}_{\text {mean }}$

$$
\begin{aligned}
& =0.1936+0.2069+0.2067-2 * 0.1729 \\
& =0.2614
\end{aligned}
$$

The actual GRG optimum value is 0.289 , and the predicted value is 0.2614 . The error is 0.0276 , and then the percentage of error is 9.55 .

\section{1 Fracture Analysis:}

The fracture UTS specimens are considered to study the fracture performance of FSW specimens. The microstructural topographies of the fracture surfaces are evaluated by using SEM. The SEM photographs of standard specimens are presented in Figures 6 (a) and (b). As presented, the fracture specimen surface shows a dimpled structure, signifying a ductile failure. The occurrence of countless twisted, deformed dimples shows plastic deformation earlier failure. Large quantities of dimples on the fracture surface of the Normal FSW are seen.

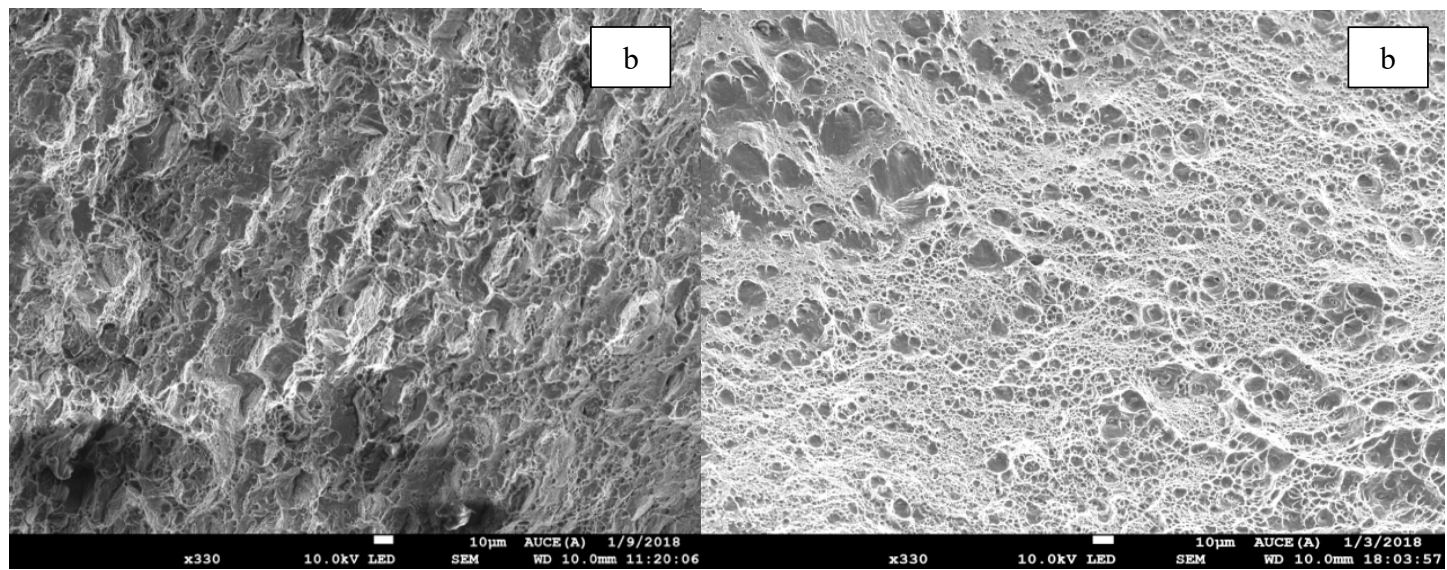

Figure 6. SEM images. a)Submerged FSW, $1400 \mathrm{rpm}, 22 \mathrm{~mm} / \mathrm{min}$. b)Normal FSW $1400 \mathrm{rpm}, 22 \mathrm{~mm} / \mathrm{min}$.

While the fracture specimens of the weld joints perform ductile features utilizing a manner to control dimples, the size and penetration of the dimples in the fracture surface of the joints welded in the air (Fig. 6a) are altered from those of the joints welded in water (Fig. 6b), looking small and even. These signify high UTS and are steady with the results. The SEM analysis of the optimum shows that more density of the microscopic grains about the 
center welds line specifies superior strength. The tensile specimen is fractured to the retreating side with 45 degrees inclination.The EDS shows the chemical composition of optimum welding processes in Fig.7.
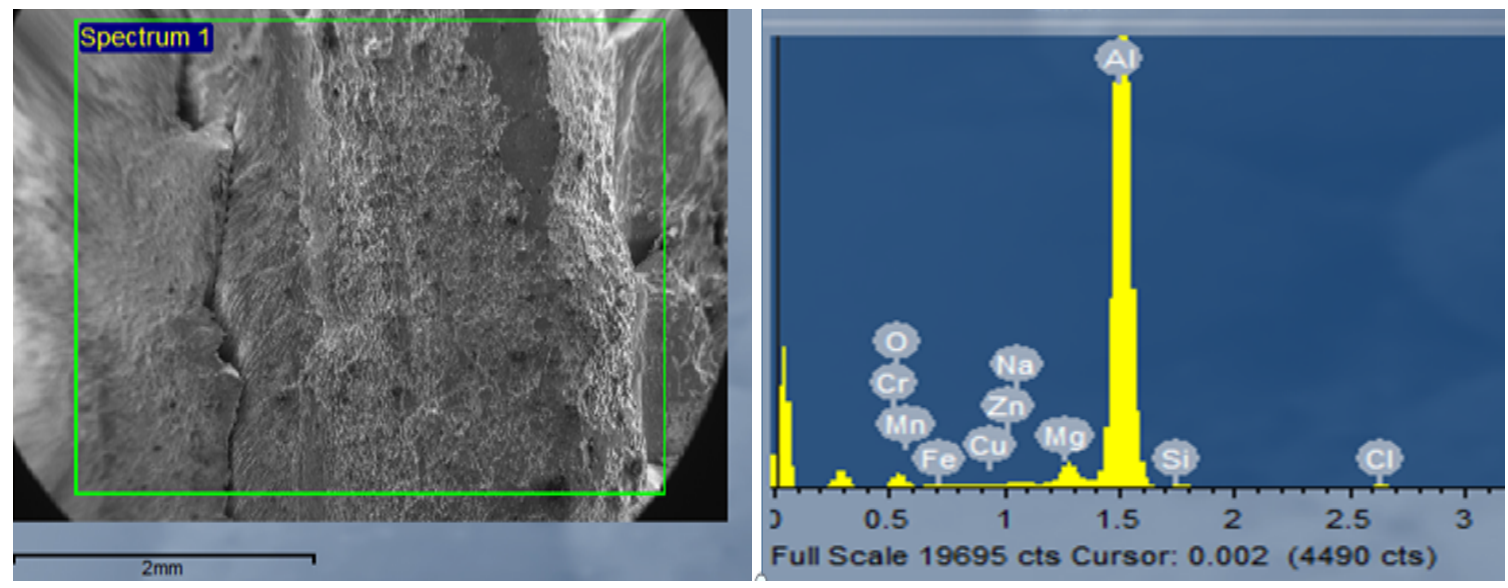

Figure 7. EDS for optimum process parameters Submerged FSW, $1400 \mathrm{rpm}, 22 \mathrm{~mm} / \mathrm{min}$.

\section{CONCLUSION}

In this analysis, the Taguchi method has been applied for responses individually $\%$ of the contribution. The significance of every process parameter is distinguished by using ANOVA. Taguchi-based GRA has been utilized for multi-objective process parameters for FSW AA5083. From this investigation, the accompanying results are acquired.

1. The possible process parameters in favor of maximum UTS, microhardness, and minimum surface roughness of the FSW weld bead are at $1400 \mathrm{rpm}$ of TRS, $22 \mathrm{~mm} / \mathrm{min}$ of TTS, and Submerged FSW.

2. The ANOVA of GRG of UTS, Ra, and HV are observed using the percentage of contributions. The type of weld conditions, TRS, and TTS are $10.69 \%, 34.28 \%$, and $30.91 \%$, respectively.

3. Hence, we can obtain good welds of higher strength and hardness by controlling parameters in a sequence of higher TRS, submerged FSW, and low TTS.

4. The tensile strength of the Submerged FSW sample occurred nearer to the base material strength. It indicates that sufficient heat is generated in submerged FSW conditions.

5. The SEM analysis of the optimum level fractured specimen shows that more density of the microscopic grains specifies superior strength, and the tensile test specimen is fractured to the retreating side with $45^{0}$ inclinations.

\section{ACKNOWLEDGMENT}

Thanks are due to DST Project SB/FTP/ETA-284/2012, for conducting the Friction Stir Welding Experiment. 


\section{REFERENCES}

Sree Sabari, S., et al. 2016. Experimental and Numerical Investigation on Under-Water Friction Stir Welding of Armour Grade AA2519-T87 Aluminium Alloy. Defence Technology, vol. 12, no. 4, Elsevier B.V., 2016, pp. 324-33, doi:10.1016/j.dt.2016.02.003.

Sabari, S. Sree, et al. 2016. Influences of Tool Traverse Speed on Tensile Properties of Air Cooled and Water Cooled Friction Stir Welded AA2519-T87 Aluminium Alloy Joints. Journal of Materials Processing Technology, vol. 237, Elsevier B.V., 2016, pp. 286-300, doi:10.1016/j.jmatprotec.2016.06.015.

Fujii, H.; Cui, L.; Maeda, M.; Nogi, K. 2006. Effect of tool shape on mechanical properties and microstructure of friction stir welded aluminum alloys. Materials Science and Engineering A 2006, 419, $25-31$.

Suresha, C. N., et al. 2011. A Study of the Effect of Tool Pin Profiles on Tensile Strength of Welded Joints Produced Using Friction Stir Welding Process. Materials and Manufacturing Processes, vol. 26, no. 9, 2011, pp. 1111-16, doi:10.1080/10426914.2010.532527.

Darras B and Kishta E. 2013. Submerged friction stir processing of AZ31 magnesium alloy. Mater Design 2013; 47: 133-137

Hofmann D and Vecchio K. 2005. Submerged friction stir pro- cessing (SFSP): an improved method for creating ultra- fine-grained bulk materials. Mater Sci Eng A 2005; 402: 234-241.

S. Shanavas, J. Edwin Raja Dhas, and N. Murugan. 2018. Weldability of marine grade AA 5052 aluminum alloy by underwater friction stir welding, Int. J. Adv. Manuf. Technol., vol. 95, no. 9-12, pp. 4535-4546, doi:10.1007/s00170-017-1492-6.

Pedapati, S. R., Paramaguru, D., \& Awang, M. (2017). Microhardness and Microstructural Studies on Submerged Friction Stir Welding of 5052 Aluminum Alloy. Volume 2: Advanced manufacturing.doi:10.1115/imece2017-71248.

Jata, K.V.; Semiatin, S.L. 2000. Continuous dynamic recrystallization during friction stir welding of high strength aluminum alloys. Scripta Materialia 2000, 43, 743.

Liu, G.; Murr, L.E.; Niou, C.S.; McClure, J.C.; Vega, F.R. 1997. Micro structural aspects of the friction stir welding of 6061-T6 aluminum. Scripta Materialia, 37, 355.

M. Koilraj a, V. Sundareswaran b, S. Vijayan c, S.R. Koteswara Rao d. 2012. Friction stir welding of dissimilar aluminum alloys AA2219 to AA5083 - Optimization of process parameters using Taguchi technique Materials and Design 42 (2012) 1-7 doi:10.1016/j.matdes.2012.02.016.

Khalkhali, Abolfazl, Morteza Sarmadi, and Ehsan Sarikhani. 2017. Investigation on the Best Process Criteria for Lap Joint Friction Stir Welding of AA1100 Aluminum Alloy via Taguchi Technique and ANOVA, Proceedings of the Institution of Mechanical Engineers, Part E: Journal of Process Mechanical Engineering, 231.2,329-42. https://doi.org/10.1177/0954408916665651.

Taguchi G and Konishi S. Orthogonal arrays and linear graphs, tools for quality engineering. MI, USA: American Supplier Institute (ASI), 1987, 72 pp.

Taguchi G. 1986. Introduction to quality engineering. New York: Kraus International Publication.

J. Deng. 1989. Introduction to the grey system. J Grey Systems, $1-24$.

Dinesh Kumar, R., M. S. Ilhar UI Hassan, S. Muthukumaran, T. Venkateswaran, and D. Sivakumar. 2019. Single and Multi-Response Optimization and Validation of Mechanical Properties in Dissimilar Friction Stir Welded AA2219-T87 and AA7075-T73 Alloys Using T-GRA, Experimental Techniques, 43.3 (2019), 245-59, https://doi.org/10.1007/s40799-019-00305-3. 
Vijayan, Sundaravel, et al. 2010. Multiobjective Optimization of Friction Stir Welding Process Parameters on Aluminum Alloy AA 5083 Using Taguchi-Based Grey Relation Analysis. Materials and Manufacturing Processes, vol. 25, no. 11, pp. 1206-12.

Asadi, P., Akbari, M., Givi, M. K. B., \& Panahi, M. S. (2016). Optimization of AZ91 friction stir welding parameters using Taguchi method. Proceedings of the Institution of Mechanical Engineers, Part L: Journal of Materials: Design and Applications, 230(1), 291-302. https://doi.org/10.1177/1464420715570987.

Huu, Phan Nguyen. (2020). 'Multi-Objective Optimization in Titanium Powder Mixed Electrical Discharge Machining Process Parameters for Die Steels'. Alexandria Engineering Journal 59(6): 4063-79.

Huu Phan, Nguyen, and T. Muthuramalingam. (2021). 'Multi Criteria Decision Making of Vibration Assisted EDM Process Parameters on Machining Silicon Steel Using Taguchi-DEAR Methodology'. Silicon 13(6): 1879-85.

Long, Banh Tien, Nguyen Huu Phan, Ngo Cuong, and Vijaykumar S. Jatti. (2016). 'Optimization of PMEDM Process Parameter for Maximizing Material Removal Rate by Taguchi's Method'. International Journal of Advanced Manufacturing Technology 87(5-8): 1929-39.

Nguyen, Huu Phan, Ngoc Vu Ngo, and Quoc Tuan Nguyen. (2021). 'Optimizing Process Parameters in Edm Using Low Frequency Vibration for Material Removal Rate and Surface Roughness'. Journal of King Saud University - Engineering Sciences 33(4): 284-91.

Nguyen, Huu Phan, Van Dong Pham, and Ngoc Vu Ngo. (2018). 'Application of TOPSIS to Taguchi Method for Multi-Characteristic Optimization of Electrical Discharge Machining with Titanium Powder Mixed into Dielectric Fluid'. International Journal of Advanced Manufacturing Technology 98(5-8): 1179-98.

S. Kasman. 2019. Identification of the Pin Offset Effect on the Friction Stir Welding (FSW) via Taguchi - Grey Relational Analysis: A Case Study for AA 7075 - AA 6013 Alloys', Materialwissenschaft Und Werkstofftechnik, 50.11, 1364-81 https://doi.org/10.1002/mawe.201800118. 